\title{
Comparison of dexmedetomidine and lignocaine on attenuation of airway and pressor responses during tracheal extubation
}

\author{
Vivek Bharti Sharma, Hemanshu Prabhakar, Girija Prasad Rath, Parmod Kumar Bithal
}

\begin{abstract}
Background: Haemodynamic stability and rapid emergence after general anaesthesia used in spinal surgery is a common practice, the goal of which is to permit early neurological motor and sensory examination. Extubation is almost always associated with hypertension, increased airway response and arrhythmias. We have compared the effects of the $\alpha-2$ agonist Dexmedetomidine and Lignocaine given at the end of the procedure on attenuation of airway and pressor responses following tracheal extubation. This study is a randomised, placebo-controlled, double-blinded study. Materials and Methods: Sixty ASA I-III patients, aged I8-70 years, scheduled to undergo spinal surgery at the level of thoracic, lumbar or sacral region were randomly divided into three groups. Balanced general anaesthesia comprising standard procedures and drugs were used for monitoring, induction and maintenance. At the last skin suture, inhalation anaesthetic was discontinued. After turning the patient supine and return of spontaneous efforts, in Group D Dexmedetomidine $0.5 \mu \mathrm{g} / \mathrm{kg}$, in Group L Lignocaine $1.5 \mathrm{mg} / \mathrm{kg}$ and in Group P normal saline $(10 \mathrm{ml})$ were administered as bolus intravenously over 60 seconds. Systolic, diastolic and mean arterial pressures and heart rate were recorded before intravenous administration and also every minute for 3 minutes, at 5, 10 and 15 minutes post-extubation. Duration of emergence and extubation were noted and attenuation of airway response and quality of extubation was evaluated on cough grading. Results: Mean arterial pressures and heart rate were higher in Group $L$ and Group $P$ than in Group $D$ but not statistically significant. The duration of emergence, extubation and recovery were comparable in all the groups $(P>0.05)$. Extubation Quality Scores was I in $80 \%, 2$ in $20 \%$ in Group D; in Group L, the quality scores were I for $55 \%, 2$ for $45 \%$ and I Group P I for $35 \%, 2$ for $45 \%$ and 3 for $20 \%$ of the patients. The requirement of rescue analgesia was also less and after prolonged time in Group $D$ than in Group $L$ and Group $P(P<0.05)$. None of the patients in all three groups showed respiratory depression, allergic reactions, nausea, vomiting or shivering. There was occurrence of hypertension for the initial 3 minutes of administration of drug in $10(50 \%)$ of patients in Group D (Dexmedetomidine) group. Conclusion: Without interfering in emergence and extubation times, attenuation of pressor response is comparable between Dexmedetomidine $0.5 \mu \mathrm{g} / \mathrm{kg}$ and Lignocaine $1.5 \mathrm{mg} / \mathrm{kg}$ but airway response is much better controlled allowing a smooth easy extubation providing a more comfortable recovery and early neurological examination following spinal surgeries.
\end{abstract}

Key words: Airway responses, dexmedetomidine, haemodynamics, lignocaine, tracheal extubation

\begin{tabular}{|l|l|}
\hline \multicolumn{2}{|c|}{ Access this article online } \\
\hline Quick Response Code: & Website: \\
\hline & www.jnaccjournal.org \\
\cline { 2 - 2 } & \\
\hline
\end{tabular}

\section{INTRODUCTION}

Tracheal extubation is almost always associated with haemodynamic changes due to reflex sympathetic discharge caused by epipharyngeal and laryngopharyngeal stimulation. This increase in sympatho-adrenal activity may result in hypertension, tachycardia and arrhythmias. ${ }^{[1,2]}$

Department of Neuroanaesthesiology, Neurosciences Center, All India Institute of Medical Sciences, New Delhi, India

Address for correspondence:

Dr. Hemanshu Prabhakar, Department of Neuroanaesthesiology, Neurosciences Center, All India Institute of Medical Sciences New Delhi - 110029 , India. E-mail: prabhakarhemanshu@rediffmail.com 
This increase in blood pressure and heart rate are usually transitory, variable and unpredictable. It is more hazardous to the patient with hypertension, myocardial insufficiency or cerebrovascular diseases. ${ }^{[3]}$ At the same time, airway irritation appearing during tracheal extubation may cause cough or difficulties in breathing and may contribute to an increase in blood pressure. ${ }^{[4,5]}$ Smooth tracheal extubation requires the absence of straining, movement, coughing, breath holding or laryngospasm. ${ }^{[6]}$ Various techniques and antihypertensive drugs are available to attenuate airway and circulatory reflexes during extubation but none have been completely successful. ${ }^{[7-10]}$ Attempts have been made to attenuate the pressor response by the use of drugs such as narcotic analgesics, deep anaesthesia induced by inhalational anaesthetics, local anaesthetics, adrenoceptor blockers and vasodilator agents. ${ }^{[1]}$ Studies have been carried out with use of diltiazem, ${ }^{[1-3]}$ lignocaine,,$^{[2,7-10]}$ esmolol, ${ }^{[11]}$ labetalol, ${ }^{[12]}$ nicardipine, ${ }^{[13]}$ and opioids ${ }^{[14]}$ as sole agent or in comparison with each other. To attenuate airway and pressor response during tracheal extubation, dexmedetomidine, a, highly selective alpha-2 adrenoceptor agonist has been studied as single dose, ${ }^{[15,16]}$ at the time of extubation and as an anaesthetic adjuvant. ${ }^{[16-20]}$ It has a sympatholytic effect through decreases in concentration of norepinephrine. This, in turn, decreases the blood pressure (BP) and the heart rate (HR) ${ }^{[21-23]}$ Dexmedetomidine, therefore, is theoretically appropriate for reducing airway and circulatory reflexes during emergence from anaesthesia. Lignocaine, an amide local anaesthetic, injected intravenously or topically applied to larynx and trachea, is variably effective at blunting the haemodynamic response to tracheal stimulation. ${ }^{[9,10]}$ It also prevents the rise in intracranial pressure associated with tracheal suctioning and may prevent the rise in intraocular pressure seen with tracheal intubation. It also decreases intracellular calcium concentration in airway smooth muscle, decreases myofilament calcium sensitivity and has been shown to suppress coughing and prevent reflex bronchoconstriction.

Rapid emergence after general anaesthesia used in spinal surgery is a common practice, the goal of which is to permit early neurological motor and sensory examination. To date no study has compared dexmedetomidine and lignocaine, in attenuating cardiovascular and airway reflexes during extubation in patients undergoing spinal surgery. The aim of this randomised, placebo-controlled, double-blinded study was to compare the efficacy of dexmedetomidine and lignocaine on attenuation of airway and pressor responses following tracheal extubation.

\section{MATERIALS AND METHODS}

The study was conducted on 60 adult patients aged 18-60 years undergoing elective spinal surgeries at thoracic, lumbar and sacral levels. All patients with ischaemic and/ or congestive cardiac disease, renal, hepatic and respiratory dysfunction were excluded. Patients were also excluded from the study if they were being treated with drugs like $\beta$-blockers, digoxin, $\alpha 2$-agonists, anticonvulsants or psychotropic medications. Other exclusion criteria included patients with $\mathrm{HR}$ below $60 / \mathrm{min}$ or arterial pressure less than $100 / 60 \mathrm{mmHg}$ and history of allergic reactions to study drugs. Patients who required postoperative mechanical ventilation were also excluded.

The human ethics and research committee of our institute approved the study protocol. Written informed consent was obtained from all patients. All patients received glycopyrrolate $0.2 \mathrm{mg}$ intramuscular as premedication before being shifted to the operation theatre. Monitoring in the operation theatre consisted of 5-lead electrocardiography, heart rate (HR), pulse oxymetry and non-invasive blood pressure. Intravenous (IV) access was established with 18-G cannula.

General anaesthesia was induced with fentanyl $2 \mu \mathrm{g} / \mathrm{kg}$, followed by propofol $1.5-2 \mathrm{mg} / \mathrm{kg}$. Tracheal intubation was facilitated with rocuronium $1 \mathrm{mg} / \mathrm{kg}$. All the patients were mechanically ventilated at a fresh gas flow of $2 \mathrm{~L} / \mathrm{min}$ to maintain an end-tidal carbon dioxide $\left(\mathrm{EtCO}_{2}\right)$ of $35-40 \mathrm{mmHg}$. Anaesthesia was maintained with isoflurane in nitrous oxide and oxygen (60:40) [Minimum Alveolar Concentration (MAC)-0.8-1.0]. The left radial artery was cannulated using 20-G cannula for continuous arterial pressure monitoring. Normothermia was maintained using a forced-air warming blanket. Vecuronium in a dose of $0.03 \mathrm{mg} / \mathrm{kg}$ was given every 30-40 min to maintain muscle relaxation. Both groups received fentanyl $1 \mu \mathrm{g} / \mathrm{kg}$ every hour and for an increase in HR or systolic BP $20 \%$ above the preincisional value sustained for 1 minute. Ringer lactate, normal saline and colloids were used for replacement and maintenance. Blood and blood products were used, if required. The values for heart rate, systolic arterial pressure, diastolic arterial pressure and mean arterial pressure (MAP) obtained just before administration of the study drug were used as baseline.

A computer-generated randomisation chart was used to assign each patient to either the dexmedetomidine group (Group D, $n=20$ ), lignocaine group (Group L, $n=20$ ) or placebo group (Group P, $n=20$ ). Patients in Group D received $0.5 \mu \mathrm{g} / \mathrm{kg}$ dexmedetomidine (diluted to $10 \mathrm{ml}$ ), Group L patients received lignocaine $1.5 \mathrm{mg} / \mathrm{kg}$ (diluted to $10 \mathrm{ml}$ ) and Group P patients' received $10 \mathrm{ml}$ of normal saline. A sealed opaque envelop method was used to conceal allocation of the patients.

All study drugs were prepared in identical 10-ml syringes in equal volume by an anaesthesiologist 
who was part of the study but not involved in the anaesthetic management of the patient. The attending anaesthesiologist recording the data was also blinded to the study drug. At the last skin suture, inhalation anaesthetic was discontinued. After dressing of the surgical wound, patient was turned supine. On return of spontaneous efforts, study drugs were administered over 60 seconds and nitrous oxide was discontinued. Neuromuscular block was reversed with neostigmine $0.05 \mathrm{mg} / \mathrm{kg}$ and glycopyrrolate $0.01 \mathrm{mg} / \mathrm{kg}$. The trachea was extubated when patient followed commands. Maximum rise of HR and MAP were noted during tracheal extubation. Haemodynamic variables were noted before administering study drug and then every minute for 3 minutes, at 5, 10 and 15 minutes after the administration of the study drug. The emergence and extubation times were noted.

Emergence time was defined as time interval between discontinuing of anaesthetic and patient following verbal commands. Extubation time was defined as the time interval between cessation of anaesthetics and tracheal extubation.

Grading of cough was noted as a measure of extubation quality and recovery response. Coughing after extubation was assessed using a 5-point scale: (1) No cough, easy breathing; (2) Slight coughing (one or two), easy breathing; (3) moderate coughing (three or four); (4) heavy coughing, breathing hard and (5) laryngospasm, severe coughing and hardly breathing. ${ }^{[16]}$

Various complications such as desaturation, breathe holding, laryngospasm, bronchospasm, bradycardia, hypotension, nausea, vomiting, restlessness, etc., were noted. The total dose of fentanyl used during surgery was noted. The time to first analgesic requirement was noted. Modified Aldrete Score was noted for recovery in postanaesthesia care unit. All patients were shifted to the neurosurgical ICU for supportive care.

Statistical analysis was done using SPSS version 15.0. Data are presented as Mean (SD) or number (\%). The qualitative data was compared by applying Chi-Square or Fishers exact test. The quantitative data was compared by applying one-way ANOVA followed by post hoc comparison by Bonferroni method. To see the change over period of time, repeated measure analysis was applied followed by post hoc comparison by least square deviation method separately for each group. Statistical significance was accepted at $P<0.05$.

\section{RESULTS}

A total of 60 patients were included in the study and none excluded from final analysis. The demographic profile and baseline characteristics such as HR and MAP, duration of surgery and duration of anaesthesia between the three groups were comparable $(P>0.05)$ [Table 1].

The HR increased during extubation in all three groups as compared to baseline values. The HR remained significantly high after 5 minutes of the drug administration in lignocaine group $(P=0.01)$ and placebo group [Figure 1]. Use of dexmedetomidine was associated with less increase in HR as compared to lignocaine group. Bradycardia occurred in one patient within 1 minute of drug administration in group D.

No patients in Group D or Group L showed hypertensive response. However, the MAP remained high for the initial 3 minutes after drug administration in Group D. Later it returned to baseline values. MAP was better controlled in the dexmedetomidine group than in lignocaine group [Figure 2].

Table 1: Demographic data and baseline characteristics [(mean \pm SD) or number $(\%)]$

\begin{tabular}{lcccc}
\hline Variables & $\begin{array}{c}\text { Group D } \\
(\boldsymbol{n}=\mathbf{2 0})\end{array}$ & $\begin{array}{c}\text { Group L } \\
(\boldsymbol{n}=\mathbf{2 0})\end{array}$ & $\begin{array}{c}\text { Group P } \\
(\boldsymbol{n}=\mathbf{2 0})\end{array}$ & $\boldsymbol{P}$ value \\
\hline Age (years) & $39.1 \pm 9.4$ & $42.7 \pm 13.7$ & $41.2 \pm 12.9$ & 0.65 \\
Sex (M/F) & $15 / 5$ & $10 / 10$ & $12 / 8$ & \\
ASA & $15(75)$, & $11(55)$, & $10(50)$, & \\
status I/II (\%) & $5(25)$ & $9(45)$ & $10(50)$ & \\
Weight (Kg) & $66.1 \pm 15.5$ & $63.9 \pm 14$ & $64.2 \pm 13.4$ & 0.87 \\
Basal & $83.1 \pm 18$ & $79.1 \pm 15.1$ & $79.6 \pm 8.6$ & 0.63 \\
HR (bpm) & & & & \\
Basal & $101.5 \pm 18$ & $95.8 \pm 12$ & $91.8 \pm 11.5$ & 0.1 \\
MAP (mmHg) & & & & \\
\hline
\end{tabular}

$n=$ number of patients group $\mathrm{D}$-Dexmedetomidine, $\mathrm{HR}=$ heart rate group L-Lignocaine, BPM = beats per minute group P-Placebo (Normal Saline), MAP = mean arterial pressure, Hrs = hours, ASA = American Society of Anesthesiologists, $\mathrm{SD}=$ standard deviation

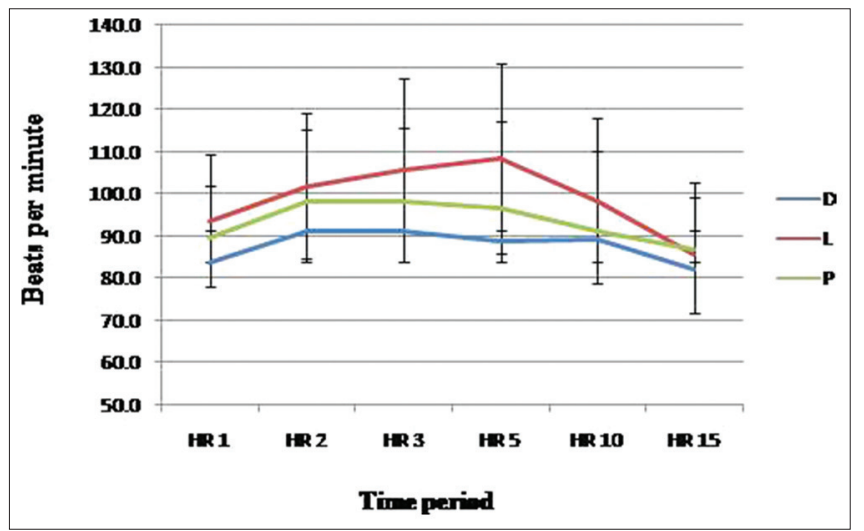

Figure 1: Changes in heart rate $(H R)$ (mean $\pm S D)$. Measurement points; HR1: 1 minute after drug administration, HR2: 2 minutes after drug administration, HR3: 3 minutes after drug administration, HR4: 5 minutes after drug administration, HR5: 10 minutes after drug administration, HR6: 15 minutes after drug administration, $\mathrm{D}=$ Dexmedetomidine, $\mathrm{L}$ = Lignocaine, $\mathrm{P}=$ Placebo 
Airway response was noted at the time of extubation. The cough grades were 1 and 2 in 16 and 4 patients, respectively, in dexmedetomidine group and 13 and 7 patients, respectively, in lignocaine group. In placebo group, it was cough grade 1, 2 and 3 in 7, 11 and 2 patients, respectively [Figure 3].

There was no difference in emergence and extubation times among the two groups $(P=0.10$ and $P=0.17)$ [Table 2]. Modified Aldrete score as assessed in the postanaesthesia care unit was comparable between the two groups $(P=0.68)$. The time to first analgesic requirement was delayed after administration of dexmedetomidine $(P<0.0001)$.

\section{DISCUSSION}

The main findings of our study are as follows

- The heart rate increased in all the groups but the increase was more in patients in Group L than in Group D. Only one patient had bradycardia in the dexmedetomidine group

- The MAP increased for the initial 3 minutes of drug administration in dexmedetomidine group. However, dexmedetomidine attenuated the increase in blood pressure to a greater degree than lignocaine

- The airway response was better attenuated with dexmedetomidine than with lignocaine

- The need for postoperative analgesia was delayed after administration of dexmedetomidine.

The haemodynamic effects of dexmedetomidine results from peripheral and central mechanisms. The $\alpha_{2 B}$-receptors located on vascular smooth muscle mediate vasoconstriction. The initial response following rapid dexmedetomidine infusion may be a transient

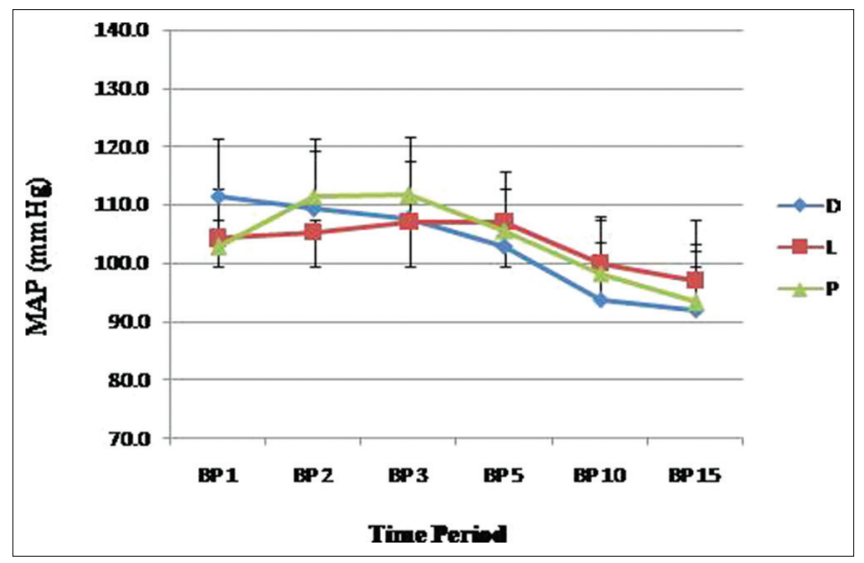

Figure 2: Changes in MAP (mean $\pm \mathrm{SD}$ ). Measurement points; BP1: 1 minute after drug administration, BP2: 2 minutes after drug administration, BP3: 3 minutes after drug administration, BP4: 5 minutes after drug administration, BP5: 10 minutes after drug administration, BP6: 15 minutes after drug administration, $\mathrm{D}=$ Dexmedetomidine, $\mathrm{L}=$ Lignocaine, $\mathrm{P}=$ Placebo hypertension. ${ }^{[21,22]}$ In our study, we observed similar result. MAPs increased in the first 2 minutes after drug administration but returned to normal values after 3 minutes. In the central nervous system, activation of $\alpha-2$ receptors leads to reduction in sympathetic outflow and an increase in vagal activity. Dexmedetomidine may have some action as a peripheral ganglionic blocker, further enhancing the sympatholytic effect. Turan et al., examined the effects of dexmedetomidine given at the end of procedure to prevent hyperdynamic responses during extubation and to allow a comfortable and high quality recovery. They found that dexmedetomidine $0.5 \mu \mathrm{g} / \mathrm{kg}$ administered 5 minutes before the end of surgery stabilised haemodynamics, allowed easy extubation, provided a more comfortable recovery and early neurological examination following intracranial operations. ${ }^{[15]}$ Guler et al., studied the effect of a single bolus dose of dexmedetomidine $0.5 \mu \mathrm{g} / \mathrm{kg}$ as bolus

Table 2: Intraoperative and postoperative data (mean \pm SD)

\begin{tabular}{lcccc}
\hline Variables & $\begin{array}{c}\text { Group D } \\
(\boldsymbol{n}=\mathbf{2 0})\end{array}$ & $\begin{array}{c}\text { Group L } \\
(\boldsymbol{n}=\mathbf{2 0})\end{array}$ & $\begin{array}{c}\text { Group P } \\
(\boldsymbol{n}=\mathbf{2 0})\end{array}$ & $\mathbf{P}$ value \\
\hline $\begin{array}{l}\text { Duration of } \\
\text { surgery (hrs) }\end{array}$ & $3.2 \pm 1.1$ & $3.0 \pm 1.3$ & $3.7 \pm 1.2$ & 0.48 \\
$\begin{array}{l}\text { Duration of } \\
\text { anaesthesia (hrs) }\end{array}$ & $4.4 \pm 1.1$ & $4.34 \pm 1.4$ & $4.8 \pm 1.2$ & 0.23 \\
$\begin{array}{l}\text { Fentanyl } \\
\text { intraop ( } \mu \text { g) }\end{array}$ & $210 \pm 34.8$ & $211.3 \pm 66.1$ & $226 \pm 41.4$ & 0.5 \\
$\begin{array}{l}\text { Emergence } \\
\text { time (mins) }\end{array}$ & $7.7 \pm 3.8$ & $6.5 \pm 1.9$ & $5.9 \pm 1.8$ & 0.1 \\
$\begin{array}{l}\text { Extubation } \\
\text { time (mins) }\end{array}$ & $9.2 \pm 4$ & $7.9 \pm 1.9$ & $7.5 \pm 2.2$ & 0.17 \\
$\begin{array}{l}\text { Modified } \\
\text { Aldrete score }\end{array}$ & $9.8 \pm 0.4$ & $9.8 \pm 0.4$ & $9.4 \pm 0.6$ & 0.68 \\
$\begin{array}{l}\text { Time to first } \\
\text { analgesic (mins) }\end{array}$ & $20.4 \pm 9.8$ & $10.8 \pm 7.9$ & $9.2 \pm 9.4$ & $<0.000$ \\
\hline
\end{tabular}

$\mu \mathrm{g}=$ micrograms, mins $=$ minutes, $\mathrm{hrs}=$ hours

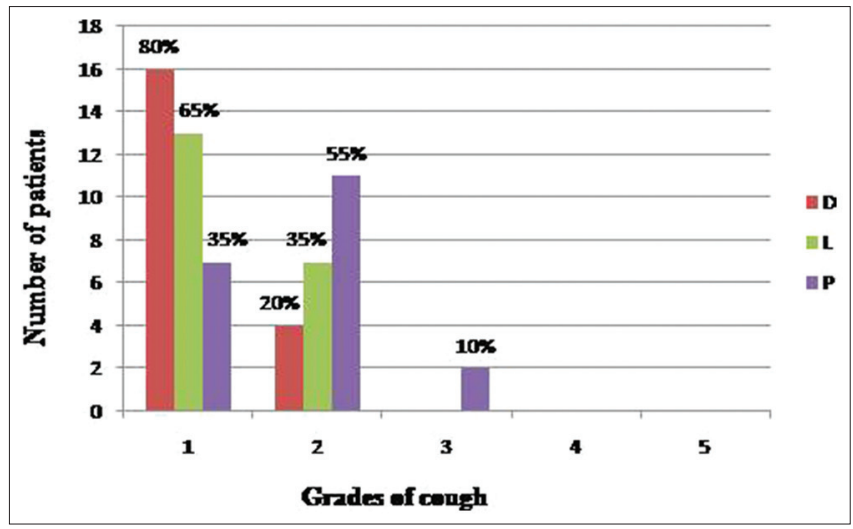

Figure 3: Different grades of cough observed in the three groups. $1=$ Grade 1, $2=$ Grade 2, $3=$ Grade 3, $4=$ Grade 4 and $5=$ Grade $5, \mathrm{D}=$ Dexmedetomidine, $\mathrm{L}=$ Lignocaine, $\mathrm{P}=$ Placebo 
intravenously over 60 seconds in patients undergoing intraocular surgery. The authors' findings suggested that a single bolus dose of dexmedetomidine before tracheal extubation attenuated airway-circulatory reflexes during extubation without affecting emergence time, an effect possibly mediated via its sedative and analgesic properties. ${ }^{[16]}$ In the same study, one patient had bradycardia and three had hypotension. In our study, one patient had bradycardia and no hypotension was observed.

Tanskanen et al., observed that decrease in the hypertensive response to extubation was related to the dose of dexmedetomidine used as intravenous infusion; a higher dose was more effective than a lower dose in 54 patients undergoing supratentorial brain tumor surgery. ${ }^{[20]}$ In our study, also we found that a single bolus dose was effective at the end of the procedure.

The net effect of $\alpha-2$ adrenoceptor action is a significant reduction in circulating catecholamines, modest reduction in blood pressure and modest reduction in heart rate. Dexmedetomidine is known to decrease the concentration of catecholamine and in particular, norepinephrine in the blood, and inhibits the secretion of catecholamine against a noxious stimulus.

Turan et al., studied the effects of two different doses of dexmedetomidine during the extubation period in patients operated for intracranial lesions. They concluded that dexmedetomidine used in a dose of $0.5 \mu \mathrm{g} / \mathrm{kg}$ in $1 \mathrm{~min}$ before extubation is a suitable agent for optimal haemodynamic state and good recovery condition for intracranial operations. ${ }^{[24]}$

Alpha 2-agonists have been recognised as having analgesic effects. Arain et al., studied 34 patients scheduled for elective inpatient surgery who received dexmedetomidine $(1 \mu \mathrm{g} / \mathrm{kg}$ loading dose over $10 \mathrm{~min}$ followed by $0.4 \mu \mathrm{g} / \mathrm{kg}$ for 4 hours) or morphine sulfate $0.08 \mathrm{mg} / \mathrm{kg} 30 \mathrm{~min}$ before the end of surgery. They concluded that dexmedetomidine significantly reduced opioid requirements by $66 \%$ in the postoperative period. ${ }^{[25]}$ In this study we also noted down the time to first analgesic after extubation which was significantly delayed $(P<0.0001)$ after administration of the bolus dose of dexmedetomidine. In contrast to other studies, we are not sure whether a single bolus dose of dexmedetomidine will be as effective to delay the time to first analgesic. This area needs to be explored and further investigated because previous studies have either used infusions which were started at least 30 minutes before the end of surgery or multiple bolus doses.

\section{LIMITATIONS}

Our study is not without limitations. We studied single doses of lignocaine and dexmedetomidine for attenuation of haemodynamic and airway reflexes. A dose-response study may be useful in determining the appropriate dose of the study drugs. Secondly, we used boluses of the study drug. It is likely that the response would have been varied if the drugs were administered as infusion. Another limitation is the small sample size. However, for more than $80 \%$ power, we required a sample size of about 80 patients in each group which was logistically difficult for us.

\section{CONCLUSION}

We conducted this prospective, randomised, double blind, placebo-controlled study to compare the effects of dexmedetomidine and lignocaine hydrochloride on attenuation of pressor and airway responses during tracheal extubation. Without interfering in emergence and extubation times, attenuation of pressor response is comparable between dexmedetomidine $0.5 \mu \mathrm{g} / \mathrm{kg}$ and lignocaine $1.5 \mathrm{mg} / \mathrm{kg}$. However, airway response was better controlled with use of dexmedetomidine allowing a smooth easy tracheal extubation, thereby providing a more comfortable recovery and early neurological examination.

\section{REFERENCES}

1. Nishina K, Mikawa K, Maekawa N, Obara H. Attenuation of cardiovascular responses to tracheal extubation with diltiazem. Anesth Analg 1995;80:1217-22.

2. Fuji Y, Saitoh Y, Takahashi S, Tayooka H. Combined diltiazem and lidocaine reduces cardiovascular responses to tracheal extubation and anesthesia emergence in hypertensive patients. Can J Anaesth 1999;46:952-6.

3. Mikawa K, Nishina K, Maekawa N, Obara H. Attenuation of cardiovascular responses to tracheal extubation; Verapamil v/s Diltiazem. Anesth Analg 1996;82:1205-10.

4. Cranfield KA, Bromley LM. Minimum alveolar concentration of desflurane for tracheal extubation in deeply anaesthetized, unpremedicated children. Br J Anaesth 1997;78:370-1.

5. Miller KA, Harkin CP, Bailey PL. Postoperative tracheal extubation. Anesth Analg 1995;80:149-72.

6. Nishina K, Mikawa K, Shiga M, Maekawa N, Obara $H$. Prostaglandin E1 attenuates the hypertensive response to tracheal extubation. Can J Anaesth 1996;43:678-83.

7. Nishina K, Mikawa K, Maekawa N, Obara H. Fentanyl attenuates cardiovascular responses to tracheal extubation. Acta Anaesthesiol Scand 1995;39:85-9.

8. Baraka A. Intravenous lidocaine controls extubation laryngospasm in children. Anesth Analg 1978;57:506-7.

9. Jee D, Park SY. Lidocaine sprayed down the endotracheal tube attenuates the airway-circulatory reflexes by local anesthesia during emergence and extubation. Anesth Analg 2003;96:293-7.

10. Minogue SC, Ralph J, Lampa MJ. Laryngotracheal topicalization with lidocaine before intubation decreases the incidence of coughing on emergence from general anaesthesia. Anesth Analg 2004;99:1253-7.

11. Dyson A, Isaac PA, Penant JH, Giesecke AH, Lipton JM. Esmolol attenuates cardiovascular responses to extubation. Anesth Analg 1990;71:675-8. 
12. Muzzi DA, Black S, Losasso TJ, Cucchiara RF. Labetolol and esmolol in the control of hypertension after intracranial surgery. Anesth Analg 1990;70:68-71.

13. Kovac AL, Masiongale A. Comparison of Nicardipine versus esmolol in attenuating the haemodynamic response to anesthesia emergence and extubation. J Cardiothorac Vasc Anesth 2007;21:45-50.

14. Sadegi M, Firozian A, Ghafari MH, Eefehani F. Comparison in effect of intravenous alfentanil and lidocaine on airway-circulatory reflexes during extubation. Int J Pharmacol 2008;4:223-6.

15. Turan G, Ozgultekin A, Turan C, Dincer E, Yuksel G. Advantageous effects of Dexmedetomidine on haemodynamic and recovery reponses during extubation for intracranial surgery. Eur J Anaesthesiol 2008;25:816-20.

16. Guler G, Akin A, Tosun Z, Eskitascoglu E, Mizra A, Boyaci A. Single-dose dexmedetomidine attenuates airway and circulatory reflexes during extubation. Acta Anaesthesiol Scand 2005;49:1088-91.

17. Lawrence $\mathrm{CJ}$, De Lange $\mathrm{S}$. Effects of a single pre-operative dexmedetomidine dose on isoflurane requirements and peri-operative haemodynamic stability. Anaesthesia 1997;52:736-44.

18. Ebert TJ, Hall JE, Barney JA, Uhrich TD, Colinco MD. The effects of increasing plasma concentrations of dexmedetomidine in humans. Anesthesiology 2000;93:382-94.

19. Bekker AY, Basile J, Gold M, Riles T, Adelman M, Cuff G, et al. Dexmedetomidine for awake carotid endartectomy: Efficacy, hemodynamic profile, and side effects. J Neurosurg Anesthesiol 2004;16:126-35.

20. Tanskanen PE, Kytta JV, Randell TT, Aantaa RE. Dexmedetomidine as an anaesthetic adjuvant in patients undergoing intracranial tumor surgery: A double blind, randomized and placebo-controlled study. Br J Anaesth 2006;5:658-65.

21. Bloor BC, Ward DS, Belleville JP, Maze M. Effects of intravenous dexmedetomidine in humans: Part II-Hemodynamic changes. Anesthesiology 1992;77:1134-42.

22. Khan ZP, Ferguson CN, Jones RM. Alpha-2 and imidazoline receptor agonists: Their pharmacology and therapeutic role. Anaesthesia 1999;54:146-65.

23. Asai T, Koga K, Vaughan RS. Respiratory complications associated with tracheal intubation and extubation. $\mathrm{Br} \mathrm{J}$ Anaesth 1998;80:767-75.

24. Turan, C, Turan G, Ozgultekin A, Dýncer E, Yuksel G. The effects of two different doses of dexmedetomidine on extubation: 9AP3-5. Eur J Anaesthesiol 2007;24:114.

25. Arain SR, Ruehlow RM, Uhrich TD, Ebert TJ. The efficacy of dexmedetomidine versus morphine for postoperative analgesia after major in patient surgery. Anesth Analg 2004;98:153-8.

How to cite this article: Sharma VB, Prabhakar H, Rath GP, Bithal PK. Comparison of dexmedetomidine and lignocaine on attenuation of airway and pressor responses during tracheal extubation. J Neuroanaesthesiol Crit Care 2014;1:50-5.

Source of Support: Nil, Conflict of Interest: None declared.

\section{New features on the journal's website}

Optimized content for mobile and hand-held devices

HTML pages have been optimized of mobile and other hand-held devices (such as iPad, Kindle, iPod) for faster browsing speed.

Click on [Mobile Full text] from Table of Contents page.

This is simple HTML version for faster download on mobiles (if viewed on desktop, it will be automatically redirected to full HTML version)

\section{E-Pub for hand-held devices}

EPUB is an open e-book standard recommended by The International Digital Publishing Forum which is designed for reflowable content i.e. the text display can be optimized for a particular display device.

Click on [EPub] from Table of Contents page.

There are various e-Pub readers such as for Windows: Digital Editions, OS X: Calibre/Bookworm, iPhone/iPod Touch/iPad: Stanza, and Linux: Calibre/Bookworm.

\section{E-Book for desktop}

One can also see the entire issue as printed here in a 'flip book' version on desktops.

Links are available from Current Issue as well as Archives pages.

Click on View as eBook 